\title{
Sinergias e incrustación del Estado en la sociedad: la política económica alternativa del Gobierno Regional de San Martín
}

Anke Kaulard*

* Licenciada y magíster en Ciencias Regionales de América Latina por la Universidad de Colonia, Alemania. Doctoranda en Sociología y becaria del programa trAndeS - Desarrollo Sostenible y Desigualdades en la Región Andina, PUCP - FU Berlín. Correo electrónico: akaulard@pucp.edu.pe

Fecha de recepción: 17/06/2019. Fecha de aceptación: 28/11/2019. 


\title{
Sinergias e incrustación del Estado en la sociedad: la política económica alternativa del Gobierno Regional de San Martín
}

\section{RESUMEN}

El «Milagro de San Martín» en la Amazonía peruana es una metáfora conocida a nivel nacional e internacional para la recuperación del orden estatal en una región anteriormente convulsionada por el terrorismo y el narcotráfico. Con el lente del neo-institucionalismo histórico y social, este artículo explora las políticas económicas, sinergias y actores del «desarrollo alternativo « en San Martín, a quienes se le ofrece una alternativa a la coca a través de la implementación de cadenas de cacao orgánicas y de comercio justo. Este estudio encuentra que la construcción de este t de políticas, comúnmente percibida como relativamente exitosa debido a la intervención de las agencias de cooperación internacional, en realidad ha sido posible a causa de dos factores clave diferentes. Por un lado, el desarrollo de un sello propio e innovador de un Gobierno regional modernizado, que le permite ser «desarrollista en un contexto principalmente neoliberal en Perú, donde se suele restringir la intervención directa del Estado en la economía. Por otro lado, la continuidad inusual del personal del gobierno regional en diferentes períodos y su profesionalización como think and action tank en políticas agrícolas "verdes», conjuntamente con la formación de técnicos expertos, llamados «tigres» quienes contribuyeron a una política estable de cadenas de valor globales sustentables y su implementación.

Palabras clave: incrustación, sinergias, economía política regional, conocimiento de expertos, desarrollo territorial, cadenas de valor globales.

\section{Synergies and embeddedness of the State in society: The alternative economic policy of the Regional Government of San Martín}

\begin{abstract}
The «Miracle of San Martín» in the Peruvian Amazon is a metaphor that is known nationally and internationally, for the recovery of state order in a region that has been convulsed by terrorism and drug trafficking. With the lens of historical and social neo-institutionalism, this article explores economic policies, synergies and actors of «alternative development» in San Martín, who have been offered an alternative to coca by the implementation of organic and fair trade cocoa chains. This study finds that the construction of organic and fair trade cocoa chains, commonly perceived as relatively successful because of the intervention of international cooperation agencies, has been possible in fact due to two different key factors. On the one hand, the development of a proper and innovative landmark of a modernized regional government, that is permitted to be «developmental» in a mostly neoliberal context in Peru where direct state intervention in the economy is usually restricted. On the other hand, the rather unusual continuity of regional government'sstaff in different government periods and their professionalization as an agricultural "green policy think and action tank" together with the formation of technical experts called «tigers», who contributed to a stable policy of the sustainable global value chains and their implementation.
\end{abstract}

Keywords: embeddedness, synergies, regional political economy, expert knowledge, global value chains. 


\section{INTRODUCCIÓN}

La política del Gobierno Regional de San Martín (Goresam) fue dirigida por muchos años hacia la recuperación del orden estatal de esta región convulsionada por el terrorismo y el narcotráfico. Los resultados de la política empezaron a conocerse en la comunidad de desarrollo como el «Milagro de San Martín» ${ }^{1}$ porque se logró erradicar la coca ilícita en grandes partes de la región y se diseñó una política de «desarrollo alternativo", a través de la implementación de cadenas productivas de cultivos como el cacao con certificación orgánica y de comercio justo, usando paquetes tecnológicos para mejorar la productividad y crear empleo a nivel local. En contraste con otros modelos comunes de explicación del «Milagro», que resaltan como factor explicativo principal la inyección de recursos financieros por agencias de cooperación internacional, este artículo «brings back the state in» (Skocpol, 1985), como actor de influencia en la ecología y economía. El gobierno regional ha sido capaz de construir sinergias (Evans, 1995; 1996) y tejer redes para intervenir activamente en el fomento de cadenas productivas «sustentables ${ }^{2} » y$ «alternativas». En la región San Martín, la política verde de conservación promovida por el gobierno regional convergió con una ideología desarrollista que pretendía utilizar los recursos naturales de manera sostenible bajo los regímenes de conservación, como pasó también en otras partes de América Latina (Orihuela, 2017; 2019a; 2019b), a pesar de una tendencia general neoliberal en Perú que suele restringir la intervención directa del Estado en la economía ${ }^{3}$.

En diálogo con el institucionalismo social e histórico, el artículo explica de qué manera la política económica regional en San Martín se perfila y se distingue de la política general del país, y qué sinergias alcanza con la sociedad civil local y otros actores para lograr esta transformación productiva específica, que pretende ser sustentable e inclusiva en un contexto regional de historia productiva diferente. La economía

1 Existen informes financiados por organizaciones de desarrollo sobre el «Milagro de San Martín», por ej. Villarán, F. y Hurtado, F.T. (2012). El modelo de desarrollo alternativo de la región San Martín: un estudio de caso de desarrollo económico local. Lima: UNODC, así como un estudio especializado sobre el desarrollo económico regional, que hace referencia a la experiencia de San Martín, financiado por el BID/FOMIN y desarrollado por un consorcio de consultores (Mesopartner/SISTME, 2014), (documento inédito).

2 La sustentabilidad engloba los pilares de lo económico, ambiental y social, mientras que el término «sostenibilidad» se reduce en la definición utilizada en este artículo a la rentabilidad y permanencia en el tiempo.

3 Esta restricción se manifiesta por ejemplo en la Ley Orgánica de Municipalidades (LOM) donde en el artículo referido al rol del Estado subnacional en el desarrollo económico local se define el rol "promotor» relativamente difuso y poco intervencionista, para mejorar la economía local y regional y no interferir negativamente en la economía (LOM, artículo 86). No está previsto que el gobierno regional o local financie infraestructura productiva para organizaciones privadas o cooperativas, por ejemplo. Para mayor debate sobre el desarrollismo estatal, incluso en sistemas neoliberales, véase Orihuela (2019 b). 
latifundista y extensiva contribuyó de manera considerable a la vasta deforestación y la incrustación de estructuras sociales desiguales. En línea con Evans (1995), este artículo trata de las coaliciones y sinergias entre los actores públicos, privados y de la sociedad civil que participaron en la construcción de las cadenas de cacao de comercio justo y orgánico y de la incrustación del Estado en la sociedad. Son gerentes y funcionarios del gobierno regional, que anterior o posteriormente trabajaron en organismos de la cooperación u ONG, quienes formaron el think tank de la política económica regional, pero también forman parte de esta red los ejecutores de esta política, los y las expertos técnicos, que fueron indispensables para la implementación del modelo. Este artículo se enfoca en los facilitadores de un entorno favorable, parte sustancial de las sinergias, que ejercen un papel a nivel «meso» ${ }^{4}$, entendido como un rol de asistencia y apoyo a los agricultores, acopiadores, transformadores y comercializadores de las cadenas productivas agrícolas, como expresión sui generis de la "economía verde» de San Martín y explica la trayectoria histórica de este camino que se tomó.

Este trabajo tiene raíces en mi trabajo y estadías recurrentes en San Martín, a través de una agencia de desarrollo dedicada al fortalecimiento de capacidades en desarrollo territorial con el objetivo de generar iniciativas de desarrollo a través de comités de cogestión público-privados. Por la constante relación con los actores regionales y locales tanto del sector público como del sector privado y la sociedad civil desde 2002, la perspectiva de sinergias ha sido importante para mi trabajo de desarrollo y de investigación. Asimismo, este artículo retoma un estudio realizado en seis países de América Latina incluyendo el Perú, impulsado por el BID/ FOMIN que categoriza el desarrollo territorial en cuatro olas sobre la base de entrevistas cualitativas a expertos, seis talleres de construcción de sentido con expertos y expertas nacionales en la temática, así como un análisis de redes sociales (ARS). Formé parte del equipo de investigadores y fui responsable del informe nacional del Perú en el cual se utilizó data de la región San Martín, obtenida a través de focus groups y minitalleres.

El desarrollo del presente estudio en el marco de mi tesis doctoral desde 2017, está sustentado en la triangulación de información documental, entrevistas de «elite» con expertos y expertas, ONG, agencias de cooperación y representantes gubernamentales, así como data de campo recogida en entrevistas, conversaciones, observaciones no participantes y participantes, un taller con funcionarios y funcionarias del gobierno regional, así como un análisis de redes sociales (ARS).

\footnotetext{
4 El término «meso», en este contexto es promovido por una escuela neoinstitucionalista alemana, a través del DIE (Instituto Alemán de Desarrollo) y ganó importancia como elemento constitutivo del «enfoque sistémico de la competitividad» que además fue retomado por la Comisión Económica para América Latina y el Caribe (Cepal) y el BID/FOMIN en sus debates conceptuales sobre el desarrollo económico regional.
} 
Estos métodos fueron aplicados para trazar las sinergias y la incrustación Estadosociedad en el desarrollo de un sello propio de la política regional de San Martín.

El artículo está estructurado en cinco secciones: Luego de esta introducción, se establece el marco teórico con los conceptos principales de la investigación. En la sección 3 se analiza la política de desarrollo económico de los gobiernos de la región San Martín en el período de 2003 a 2016. En esta parte, se observará la perfilación del gobierno regional con una política propia. En la sección 4, argumento que en San Martín, de 2005 hasta 2016, existió relativa continuidad del personal a pesar de contar con gobiernos regionales de diferentes partidos y que se logra la creación de capital social entendido como una red de pensadores y ejecutores de la nueva política regional. En las conclusiones se discutirá de qué manera la creación de sinergias ha contribuido al logro de ganancias de desarrollo en San Martín.

\section{MARCO TEÓRICO: INSTITUCIONALISMO Y SINERGIAS}

Habiendo encontrado en la investigación empírica evidencia relevante sobre la evolución institucional a través de redes, el estudio explora la política económica regional desde la teoría del institucionalismo histórico y social. En contraste al institucionalismo económico que pone en relieve el carácter racional de los individuos en la toma de decisiones económicas (rational choice) (March, 1997), estos enfoques reducen el término de las instituciones no solo a un juego de reglas, sino también incluyen la importancia de la dependencia del sendero por un lado y delas relaciones sociales por el otro (Pierson, 2004; Greif, 2006; Scott, 2008; Skocpol, 1985). Según Orihuela (2019 a) es importante construir un puente entre el nuevo institucionalismo sociológico y el histórico para entender mejor cómo evolucionan las instituciones. El institucionalismo social postula que no se puede excluir del análisis la explicación de la influencia de redes y comunidades epistémicas (Haas, 1989), entendidas como grupos de actores que comparten un solo lenguaje y concepto temático, en la homogeneización institucional. Orihuela argumenta que estas diferentes interpretaciones de que "las instituciones 5 importan» (North, 1990) para el comportamiento social, no tienen que ser exclusivas o contradictorias. Tanto la convergencia institucional incentivada por la difusión en redes, como la divergencia institucional por la dependencia de la trayectoria aportan a y enriquecen un análisis institucional (Orihuela, 2019 a). Esto ayuda a darle un rostro más humano al institucionalismo «duro», representado por el modelo de rational choice. En este artículo se argumenta que si bien en

\footnotetext{
El término «instituciones» se refiere a las reglas que los seres humanos usan cuando interactúan con una amplia variedad de situaciones repetitivas y estructuradas en diferentes niveles de análisis (North, 2005; Ostrom, 2008).
} 
la historia productiva, ecológica y social compleja de la región San Martín, se encuentran las bases para el camino que se tomó en la política económica regional, el relativo éxito de la misma solo ha sido posible por la generación innovadora y difusión del mensaje de la «región verde y alternativa» a través de redes del Estado incrustadas en la sociedad.

En el marco teórico del institucionalismo social e histórico usaré los siguientes conceptos: las sinergias y como parte constitutiva de la misma, la incrustación (embeddedness), el enfoque de desarrollo territorial y, en relación con este, las cadenas de valor entendidas como arreglos institucionales.

El concepto de sinergias tiene dos componentes analíticas: las complementariedades y la incrustación (embeddedness) (Evans, 1996). A través de las complementariedades, el Estado provee bienes y servicios tangibles e intangibles, como por ejemplo infraestructura económica o la generación de confianza entre los actores económicos, mientras que los ciudadanos proveen el conocimiento y la experiencia local que para externos serían costosos de adquirir. Las complementariedades generalmente constituyen solo la base para las sinergias basadas en nexos que sobrepasan la división entre el sector público y privado, p.e. la incrustación, entendida como arraigo de instituciones públicas de un Estado desarrollista en una red densa de lazos sociales que permiten a las élites políticas negociar objetivos e implementar estrategias con los actores privados. La incrustación no solo constituye relaciones efectivas entre el Estado y las élites económicas en términos de desarrollo, sino también entre agencias públicas y actores menos privilegiados (Evans, 1996), como se observa en el caso del presente estudio. El concepto de la incrustación fue impregnado por Polanyi ${ }^{6}$ (2001 [1944]) y retomado por Evans $(1995 ; 1996)$ y en este estudio sirve para explicar los nexos densos de relaciones políticas y sociales del Estado regional con el sistema económico en la región de San Martín. La incrustación visualiza la permeabilidad de límites público-privadas que son importantes para el éxito de muchos programas de desarrollo (Evans, 1996). Mientras que una incrustación densa de representantes del gobierno, en este caso a nivel subnacional, con las élites locales u otros actores puede generar el riesgo de clientelismo y corrupción, los nexos también pueden constituir una fuente importante para crear capital

\footnotetext{
6 Refiriéndose fundamentalmente a la mercantilización del trabajo y la tierra en el centro del mundo a lo largo del siglo XIX, Karl Polanyi proclamó que la dinámica de la sociedad había sido "gobernada por un doble movimiento" (Polanyi, 2001, p. 136): el mercado se expandió continuamente pero este proceso fue enfrentado por un contramovimiento que dirigía la expansión en direcciones definidas. Por el contrario, si el sistema económico funcionaba solo de acuerdo con las leyes del mercado, las relaciones sociales se integrarían en el sistema económico y no al revés (Polanyi, 2001, p. 60). Al unir estas afirmaciones centrales, eventualmente surgen contramovimientos en la sociedad para (re) incorporar (embedd) el desarrollo de la economía.
} 
social, entendido como confianza y vínculos permanentes entre los actores locales, y llevar a ganancias en términos de desarrollo, por una intensa interacción del Estado con la comunidad local en un proyecto común. De esta manera, las sinergias, compuestas en una distinción analítica por la complementariedad y la incrustación son entendidas como instituciones que deben ser integradas en las teorías de desarrollo que suelen enfocarse solo en los modelos de crecimiento económico (Evans, 1996). Los dos conceptos analíticos visibilizan también el problema de estructura y agencia. Mientras que las complementariedades se refieren a factores estructurales entendidas como un «entorno favorable» para la economía local, la incrustación pone en relieve las posibilidades de interactuar y construir ganancias de desarrollo en red. ¿Cuáles son las condiciones sociales y políticas que posibilitan la sinergia? La supuesta dicotomía entre el legado y la construcción, en otras palabras, entre estructura y agencia, se matiza y hasta reconcilia, cuando se analizan los factores constituyentes y condiciones, revelados en una comparación entre varios casos realizada por Evans (1996). El capital social es una condición que facilita instancias particulares de sinergias, pero no es decisiva. Más crucial parece ser el escalamiento de la confianza entre actores locales a contextos más allá de lo local, que son eficientes para lograr ganancias de desarrollo. Factores que facilitan las sinergias son una burocracia robusta que respeta las reglas del juego de la ley, así como la competencia política en una sociedad democrática sin regímenes represores. Incluso en contextos adversos, con tácticas innovadoras institucionales es posible llegar a logros en términos de desarrollo (Evans, 1996).

El contexto en el cual se desarrollan las políticas sinérgicas del gobierno regional de San Martín desde la mitad de los años 2000, es el desarrollo territorial que en sí pone el relieve tanto la complementariedad como la incrustación. Este concepto es impregnado por la Cepal y otras organizaciones de desarrollo como el Banco Interamericano de Desarrollo (BID), el Instituto Alemán de Desarrollo (DIE) (Esser, Hillebrand, Messner y Meyer-Stamer 1994), y se entiende como un proceso de construcción social del entorno, impulsado por la interacción entre las características geofísicas, las iniciativas individuales y colectivas de distintos actores y la operación de las fuerzas económicas, tecnológicas, sociopolíticas, culturales y ambientales en el territorio (Cepal, 2019). El desarrollo territorial requiere que las estrategias sean elaboradas a partir de la movilización y participación activa de los actores territoriales. Por ello se subraya que se trata de una acción surgida «desde abajo» (Alburquerque y Pérez Rozzi, 2013). El enfoque territorial supera la mirada sectorial sobre la realidad, dotándose de una visión sistémica, esto es, que integra las diferentes dimensiones del desarrollo en un determinado ámbito territorial específico. Generalmente se connotan distintas dimensiones a este concepto, es decir, el desarrollo institucional, cultural y político, el desarrollo económico, el desarrollo ambientalmente susten- 
table, así como el desarrollo social y humano (Alburquerque y Pérez Rozzi, 2013). El territorio se entiende como un constructo social que se expresa en un espacio determinado, generalmente continuo. Ese conjunto de atributos contribuye al establecimiento de una identidad territorial (Alburquerque y Pérez Rozzi, 2013).

Las cadenas productivas no pueden verse desligadas del territorio, aunque pasen más allá del espacio local. Las asociaciones de productores y empresas no son entes aislados, sino forman parte de un entramado más complejo, a través de cadenas de relaciones (o eslabonamientos) de proveedores y clientes que van desde la utilización de materias primas básicas hasta la producción de bienes o servicios finales destinados a los mercados ${ }^{7}$ (Alburquerque y Dini, 2008).

La suposición de que las cadenas de valor con procesos eficientes, produzcan automáticamente ganancias económicas para las poblaciones locales que proveen los productos, se ha reconsiderado en gran medida en la literatura. Asimismo, estudios empíricos sobre el fairtrade y la producción orgánica, percibidas comúnmente como modelos innovadores de éxito para la justicia social y sustentabilidad ambiental, muestran resultados variados en las comunidades productoras y consumidoras (Linton, 2012; Burnyeat, 2018; Roseberry, 1996). Teóricamente, las posibles sinergias entre el Estado y el sector privado en la producción y comercialización en cadenas son conocidas y promovidas en las políticas internacionales e nacionales, por ejemplo en la Ley Orgánica de Municipalidades del Perú ${ }^{8}$. Sin embargo, la implementación de estas sinergias en casos concretos produce más desafíos.

En la literatura, el enfoque de cadenas de valor es contestado y criticado, porque se analiza como si estuviera en un vacío territorial y no se considera su integración en diferentes contextos geográficos, institucionales, políticos y sociales (Lakhani, Kuruvilla y Avgar, 2013). Orr, Donovan y Stoian (2015) subrayan que en la literatura de las cadenas productivas, hasta esa fecha solo existía conocimiento limitado sobre cómo la política, las instituciones, la cultura y el contexto local podrían moldear los posibles resultados de las intervenciones para fortalecer estos sistemas. Lane y Probert (2009) sostienen que existe una deficiente integración de enfoques institucionales en el análisis. Asimismo, se dibujarían actores estilizados que tomarían sus decisiones según el principio del «rational choice».

\footnotetext{
7 Todo ello hace posible la actividad productiva, para lo cual se requiere también de determinados insumos a fin de avanzar en las diferentes fases de la transformación del producto, incluyendo posteriormente la distribución, consumo final del producto, y el reciclaje y reutilización de los residuos producidos a lo largo de todos los eslabonamientos de dicha cadena productiva.

8 LOM, ley 27972, artículo VI. Promoción del Desarrollo Económico Local y artículo 86, 1.4. Concertar con el sector público y el privado la elaboración y ejecución de programas de apoyo al desarrollo económico local sostenible en su espacio territorial.
} 
Lakhani et al. (2013) señalan que se entiende las dinámicas de la cadena como un abstracto «entorno favorable». El aporte de Evans (1996) es el afinamiento de esta abstracción por el concepto de complementariedades y el rol del Estado en la provisión de factores tangibles e intangibles, como la provisión de infraestructura y la creación de un ambiente de confianza y seguridad para los actores económicos.

Las últimas tendencias de observar las cadenas como redes globales, pueden dar mayores aportes a rendir cuentas de la creciente complejidad. Gereffi, Humphrey y Sturgeon (2005) amplían el análisis con el concepto de redes globales, lo cual amplia el horizonte a aspectos históricos y sociales, y sobre todo menos lineales de las cadenas. Esta definición nueva fue asumida por las organizaciones de desarrollo que tienen influencia en regiones periféricas, pero están a la vez conectadas al mercado global, como en este estudio de caso.

Los conceptos de desarrollo económico local/territorial y las cadenas productivas/ de valor evolucionaron en el tiempo. De esta manera, en el diseño de los programas de apoyo al desarrollo productivo y la competitividad empresarial impulsados por el FOMIN/BID y otros organismos de cooperación al desarrollo en América Latina y el Caribe durante las dos últimas décadas, se aprecia primero una evolución desde los programas de desarrollo empresarial, cuyo foco principal se sitúa en el acceso a los servicios de desarrollo empresarial y los servicios financieros para lograr la sostenibilidad económica de las pequeńas y medianas empresas (1993-2002). En la siguiente ola, se aleja del enfoque hacia las empresas individuales y se enfoca en los programas de fomento de la integración productiva (redes empresariales, cadenas productivas y clústeres) (2003-2008). El enfoque evoluciona más hasta llegar, en la tercera ola, a un diseño integrado de programas de desarrollo económico territorial, en los cuales resulta clave el despliegue de alianzas público privadas y mecanismos de gobernanza institucional en los diferentes territorios (2009-2013) (Alburquerque y Pérez Rozzi, 2013).

Finalmente, se incluyó un nuevo desarrollo, en una cuarta etapa u ola (a partir de 2014) con políticas económicas regionales con una mirada diferente al tema ambiental y social que responde a las actuales tendencias de una globalización creciente. Se busca oportunidades a partir del cambio ambiental y la inclusión social, en el diseño de políticas económicas, así como el escalamiento de aprendizajes desde lo local a lo nacional (Mesopartner/SISTME, 2014) (Figura 1). La experiencia de San Martín ha sido promovida como una buena práctica en Perú que sirve para el desarrollo de políticas nacionales (Villarán y Hurtado, 2012; Molina y Arguedas, 2015).

Se verá a continuación que el Goresam incorporó políticas y mecanismos de intervención en la política económica en su discurso y acciones antes de que se manifestara 
con más fuerza en otras partes del Perú y América Latina, principalmente en seis países estudiados ${ }^{9}$ (Mesopartner/SISTME, 2014).

Figura 1. Las cuatro olas del desarrollo económico regional

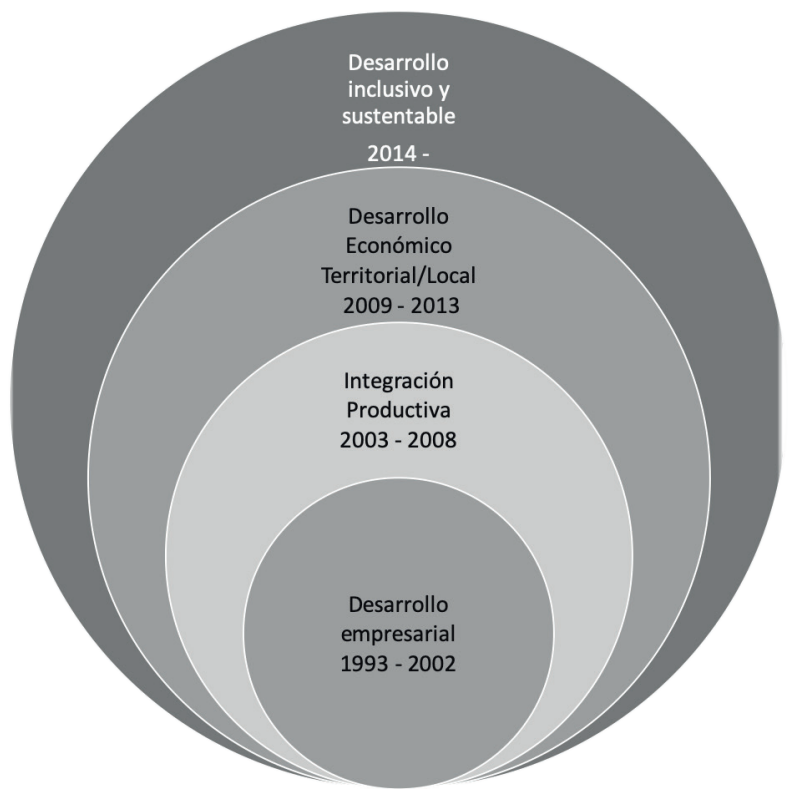

Fuente: Mesopartner/Sistme, 2014, elaboración propia.

\section{INSTITUCIONALIZANDO UNA POLÍTICA ECONÓMICA REGIONAL CON SELLO PROPIO A TRAVÉS DE SINERGIAS}

A inicios de los 2000, en Perú los procesos de desarrollo económico regional y local adquirieron importancia en el marco de los procesos de descentralización, cuando los gobiernos subnacionales asumieron más funciones y comenzaron, con mayor énfasis, a realizar políticas para resolver los problemas locales. Algunos gobiernos regionales, específicamente los que enfrentaron problemas de economías ilícitas como la coca, intervinieron de forma decidida en la economía, en un contexto generalmente neoliberal a nivel macro que trataba reducir la intervención en la economía en la mayor medida posible. El contexto económico global juega un rol importante en un giro de «redescubrimiento de lo local» y que puso en un marco mayor también a las políticas de desarrollo económico regional (DER) del Gobierno Regional de San Martín (Goresam), una región que no solo enfrentaba

9 Argentina, Bolivia, Brasil, Guatemala, México, Perú. 
el terrorismo y el narcotráfico, sino también la informalidad de la economía local y daños ambientales graves como la deforestación.

Generalmente, observadores de la política peruana afirman que el «Milagro de San Martín», ha sido protagonizado por la cooperación internacional, y no por el gobierno regional y los fobiernos locales, debido a la gran cantidad de fondos que se ha invertido, sobre todo Estados Unidos ${ }^{10}$. Sin embargo, sustento que el Goresam ha puesto un sello propio a su política «alternativa», que consiste en los siguientes elementos: desarrollo integral con visión del territorio, más allá de la competitividad económica, un enfoque de desarrollo sustentable en una «economía verde», con una concentración en la producción orgánica y (en menor grado) de comercio justo, promoción de la transformación de materia prima en chocolates y sus derivados. Como política transversal promueve el desarrollo de capacidades regionales y la educación para la economía territorial. Esta política es posible a través de las sinergias con la sociedad civil, la cooperación internacional y el sector privado.

\subsection{Desarrollo económico territorial de San Martín en un contexto de sectorialización en cadenas de commodities}

En la segunda mitad de los 2000, en el contexto de un nuevo ciclo extractivo nace el discurso del Perro del Hortelano en Perú. Se refiere a un artículo polémico escrito por el expresidente Alan García que renovó ideas discriminatorias sobre pueblos indígenas y que reclama que en Perú existen muchos recursos (naturales) sin uso que «no son transables, que no reciben inversión y que no generan trabajo. Y todo ello por el tabú de ideologías superadas, por ociosidad, por indolencia o por la ley del perro del hortelano que reza: "Si no lo hago yo que no lo haga nadie".» (García, 2007).

Este artículo causó mucho debate a nivel del país, sobre todo en cuanto al uso de los recursos naturales de la Amazonía y la relación del Estado con los pueblos indígenas ${ }^{11}$ (Espinosa, 2009).

En San Martín, la política regional, luego de la dictadura con una política neoliberal marcada, se alineaba a este contexto de explotación agraria. El primer gobierno regional, encabezado por Max Ramírez del APRA (2003-2006), fue un gobierno

\footnotetext{
10 Según la Agencia Andina (2011), USAID/Perú ha invertido más de 100 millones de dólares en San Martín entre 1996 y 2011. La mayoría de la ayuda fue para impulsar el desarrollo alternativo de las comunidades. Se logró la instalación, mantenimiento y mejora de más de 50000 hectáreas de cultivos alternativos como el cacao, café, palma, palmito y otros. La embajadora de Estados Unidos, recordó que, «debido a los éxitos obtenidos en los últimos años, San Martín ha sido considerado como un modelo de desarrollo alternativo a nivel mundial». Afirmó que "prácticamente se ha desterrado de los campos sanmartinenses los cultivos ilegales de hoja de coca» (Agencia Andina, 2011).

11 En 2009, esta situación termina en un conflicto violento entre el Ejército y la población indígena awajún y wampis, conocido como el «Baguazo» donde alrededor de treinta indígenas y militares mueren y lo cual es considerado como un desastre político y humanitario del gobierno de García.
} 
"decididamente constructivista», según el gerente de Desarrollo Económico de la época (Gallegos Arévalo, 2015). Esto quiere decir que el gobierno regional promovía la ejecución de proyectos productivos de construcción e irrigación a gran escala; por ejemplo, para «la incorporación de tierras para la explotación agraria» en la provincia de Picota. En este sentido, habría sido también un "gobierno agrarista» (Gallegos Arévalo, 2015). La política regional estaba orientada a la producción extensiva, en un modelo promovido por muchos años desde el Ministerio de Agricultura. Ramírez impulsó la política de la habilitación de tierras para la explotación agraria de productos como el maíz y arroz, y luego fue perseguido por múltiples denuncias de corrupción y dejó el gobierno prácticamente sin resultados de desarrollo que exhibir (Molina y Arguedas, 2015). En esa época, el Estado regional fue percibido como débil en su desempeño y desvinculado de las necesidades de la población. El Estado estaba incrustado en una alianza solo con los grandes terratenientes de la región y se pensó en cadenas productivas aisladas, sin mirada al territorio integral. Con el afán de construir complementariedades, el gobierno regional procuró proveer servicios como el abrimiento de trochas y la construcción de carreteras, pero en este caso, estas carreteras principalmente fueron aprovechadas por los comerciantes a gran escala que acopiaban los productos a lo largo de la carretera y no se involucró suficientemente a los pequeños productores en este tipo de desarrollo. A pesar de la corriente de agricultura a gran escala concentrada en el maíz y arroz, el Programa de Desarrollo Alternativo (PDA), implementado por la Agencia de los Estados Unidos para el Desarrollo Internacional, USAID, en cooperación con los gobiernos locales en zonas de narcotráfico en San Martín, intensificó su estrategia de fomentar la producción del cacao como alternativa a la coca en San Martín. Esta estrategia constituyó una alternativa al modelo extractivo a gran escala, ya que puso al centro a los pequeńos productores con una a tres hectáreas de tierra. Esto abrió camino a que el gobierno regional, César Villanueva (2007-2013), construyera una narrativa y política diferente. En ese momento, Villanueva es representante de la ONG ambientalista Cedisa y tiene una amplia historia como luchador de la sociedad civil organizada que en San Martín se caracteriza por la presencia histórica de una gran cantidad de ONG y asociaciones civiles. Villanueva aprovecha e integra en mayor grado que su antecesor los esfuerzos de los proyectos de desarrollo y busca sinergias con ellos.

El nuevo presidente regional enfatiza políticas de desarrollo económico territorial, a través de la expansión de cultivos alternativos a la coca, como el cacao, café y sacha inchi (Molina y Arguedas 2015) con un potencial de crecer en sistemas agroforestales, sin concentrarse en solo un o dos productos de agricultura extensiva, como lo hacía su antecesor. Su gobierno se caracteriza además por un enfoque de desarrollo de capacidades, a través de servicios de extensión agraria rural. Expande la inversión pública rural en infraestructura vial para conectar a las comunidades rurales con los 
nuevos mercados, fomentando las sinergias con la sociedad civil a través de complementariedades. Mientras que el Estado regional provee factores tangibles como la infraestructura, los actores locales-privados aportan con su conocimiento local de la agricultura para insertarse en el desarrollo territorial. Contrariamente al enfoque de cadenas productivas fomentado por el PDA, Villanueva insiste en un enfoque territorial que produzca ganancias de desarrollo no solo para los productores de un cultivo, sino para la población rural azotada por el narcotráfico en general ${ }^{12}$.

Las sinergias que crea el gobierno de Villanueva también están basadas en la incrustación. El mismo presidente regional es un ejemplo del nexo estrecho de personas del gobierno con la sociedad civil. Centrándose en la articulación entre actores de diferentes niveles del Estado, la cooperación internacional y el sector privado, Villanueva crea un think and action tank de aproximadamente quince personas quienes elaboran líneas estratégicas de desarrollo económico "sostenible» y promueven San Martín como "Región Verde». Según un asesor del ex presidente regional, la coordinación fue directa entre Villanueva y los alcaldes provinciales y distritales. Las personas que integran este grupo son por un lado colegas del mundo de las ONG que se contrataron cuando entró al gobierno ${ }^{13}$. Por su buena relación con las agencias de cooperación, el equipo de Villanueva es gradualmente complementado por expertos y expertas internacionales (Villarán y Hurtado, 2012) remunerados por organizaciones de la cooperación. Las estrategias de promoción directa a los pequeños agricultores en lugares distantes y el fomento de suagrupación en asociaciones o cooperativas demanda una gran cantidad de expertos y técnicos responsables para seleccionar los productos con mayor potencial de mercado y la extensión agraria de paquetes tecnológicos (Villarán y Hurtado, 2012).

Para pensar y desarrollar acciones estratégicas ponen mucho énfasis en el desarrollo de diagnósticos y planes económicos y que estos planes estén articulados con las políticas sectoriales y de otros niveles de gobierno, pero también internamente respaldados por un presupuesto asignado. En contraste, la política de Ramírez careció de una visión concertada con una aplicación sistemática de losinstrumentos de gestión como los planes de desarrollo y se caracterizó por una relación estrecha con los terratenientes grandes de cultivos extensivos.

Según un asesor del ex presidente regional, la coordinación es directa entre Villanueva y los alcaldes provinciales y distritales. Los políticos y funcionarios locales respetan a Villanueva y lo describen como una persona carismática con poder de

\footnotetext{
12 Entrevista con exasesor de César Villanueva, Tarapoto, febrero 2018.

13 Por ejemplo, su colega y amigo César Rengifo, le apoya como asesor y luego candidatea para la presidencia regional en 2018.
} 
convicción. «Villanueva quiso una intervención más ordenada que sea indiferente del partido y no dependa de personas» ${ }^{14}$.

Villanueva asume un rol de liderazgo y también se opone a la sectorialización de los programas de desarrollo alternativo, subrayando la necesidad de trabajar un solo plan de desarrollo para su región, no solo de desarrollo alternativo, sino para el desarrollo en general. La noción de un territorio que incorpora aspectos económicos, sociales y ambientales es un enfoque innovador para la época y rompe con la lógica de trabajar proyectos aislados de desarrollo o enfocarse en solo un "producto estrella» o una sola cadena para promover la economía local. Esta política es apoyada por las ONG de la región San Martín, que cuentan en esa época con muchos fondos de la cooperación internacional para realizar este tipo de proyectos. Un punto focal de la política económica de Villanueva es el desarrollo de capacidades, por lo cual el Goresam firma alianzas estratégicas con diferentes instituciones públicas y privadas que apoyaron a este desarrollo. Los planes de desarrollo concertados de 2008 a 2015, y en su segunda gestión, de 2013 a 2021, son construidos de forma participativa y se documenta y evalúa este proceso, lo cual también constituye una novedad en una administración pública generalmente poco dedicada a la sistematización y evaluación de sus acciones. Esta visión de desarrollo territorial regional también va más allá de los límites de San Martín porque el gobierno de Nueva Amazonía ${ }^{15}$ toma un liderazgo fuerte en la Asamblea Nacional de Gobiernos Regionales (ANGR), así como en el Consejo Interregional Amazónico (CIAM), en el que se juntaron tres regiones amazónicas "para mostrar que es posible promover el desarrollo desde las regiones» (C. Villanueva citado en Molina y Arguedas, 2015, p. 43).

A nivel regional de San Martín, se empiezan a crear poderosas asociaciones y cooperativas de productores de café y el cacao, de forma estratégica. En los años 2003 y 2004, las dos grandes cooperativas de café y cacao fundadas con fondos de la cooperación internacional en la lucha contra el cultivo de la coca, Oro Verde en el norte de San Martín (Lamas) y Acopagro en el sur (Juanjui), obtienen certificaciones orgánicas y de Fairtrade y reciben asistencia técnica y apoyo del gobierno regional. La región San Martín se adelanta a la tercera ola con esta política, promoviendo explícitamente elementos de la sostenibilidad ambiental y social. La política regional es palanqueada por diferentes programas de desarrollo de capacidades de la cooperación internacional que fortalecen la narrativa y práctica de participación,

14 Entrevista con C. Torre, febrero 2018.

15 El movimiento regional Nueva Amazonía es liderado por C. Villanueva y su colega C. Rengifo quienes conjuntamente trabajaron en la ONG Cedisa previamente. En su plan de gobierno de 2007, especifica sus principales objetivos que son: transparencia y participación en el gobierno, desarrollo humano descentralizado, mejorando nuestra calidad de vida, desarrollo económico [sostenible] para todos. (Desarrollo para todos. Plan de Gobierno Nueva Amazonía, 2007-2011, julio 2006). 
concertación y sostenibilidad. Sin embargo, la gestión de Villanueva le dará una nota propia sanmartinense, más allá de los proyectos de las agencias de desarrollo y Devida.

\subsection{La política de desarrollo sustentable adelantada de San Martín}

A nivel nacional, desde 2009 aproximadamente, se observa un rol creciente del Estado en la institucionalización de buenas prácticas de proyectos económicos regionales en programas e instrumentos del Estado a nivel central ${ }^{16}$. Recién desde esos ańos, el territorio es considerado como un espacio donde confluyen actores, sectores y políticas. La mirada sistémica del territorio supera los enfoques sectoriales de agricultura, producción, ambiente y minería/energía y trata de incluir los esfuerzos de manera concertada. Se pone atención a las diferentes formas de asociar los actores del territorio, a la gobernanza local cuyo fin es crear empleo a nivel de territorio.

En San Martín, estas ideas no fueron nuevas y ya habían sido puestas en práctica desde ańos anteriores, de manera que diferentes actores nacionales e internacionales empezaron a fijarse en el desarrollo de esta región emblemática, donde además se empiezan a mostrar los (deseados) resultados de la erradicación de la coca. Por ende, si bien la cooperación técnica internacional se reduce a partir de 2012 en general en Perú, sigue apoyando al fomento de cadenas de productos alternativos en San Martín, confiando en la continuidad de la política y los políticos en San Martín. En la llamada Economic Development Alliance (ADR) (2010-2015) entre TechnoServe (USAID), Devida y tres gobiernos regionales, entre ellos el pionero San Martín, se tiene como objetivo las técnicas de abonamiento y poda sincronizada (TAPS) y el fortalecimiento del acceso de los pequeños productores al mercado. Un nuevo concepto de cadenas de valor sistémicas con enfoque territorial se cristaliza en la región. La política de las cadenas de valor, término que es promovido en el gobierno regional y sus órganos desconcentrados Proyecto Especial Alto Mayo (PEAM) y Proyecto Especial Huallaga Central y Bajo Mayo (PEHCBM), con ayuda de la cooperación alemana (Springer-Heinze, 2017), enfatiza la creación de un valor agregado y valores éticos en la producción que implican una redistribución de los beneficios y un precio más "justo» para los y las productores/as. Este enfoque se institucionaliza gradualmente en los discursos y acciones políticas regionales y reemplaza los conceptos anteriores menos sistémicos, de las cadenas de commodities volátiles a los precios del mercado mundial. En este contexto, la segunda gestión del gobierno de Villanueva (2011-2014) concentra sus esfuerzos a nivel de política económica en siete cadenas de valor consideradas como «sustentables», con una mirada

\footnotetext{
16 Resultados del taller con expertos y expertas nacionales y regionales de Desarrollo Económico Territorial, BID-FOMIN, 2013.
} 
hacia todo el territorio, que luego serán ampliados a diez por el gobierno de Fuerza Popular bajo la presidencia de Víctor Noriega a partir de 2016.

La política de alianzas y las redes densas de los gobiernos regionales de San Martín, en distintos períodos, con la cooperación internacional e instancias a nivel nacional, como Devida y los Ministerios de Producción y Agricultura, permiten un apoyo diferenciado a todos los eslabones de las cadenas, desde la producción hasta la comercialización, en San Martín, lo cual ayuda a una creciente especialización de los recursos humanos y mejora de los servicios, así como continuidad en la arquitectura de soporte de la cadena (véase Tabla 1). La Dirección Regional Agraria (Drasam) como parte del Goresam apoya en el ordenamiento y la organización de las intervenciones, a través de espacios de concertación como las mesas técnicas, lacual reúnealos actores que brindan servicios o apoyo a las cadenas.

Tabla 1. Apoyo a la cadena de valor del cacao en San Martín

\begin{tabular}{|l|l|}
\hline Apoyo & Institución \\
\hline Investigación & $\begin{array}{l}\text { Instituto Nacional de Investigación Agraria (INIA), Instituto de Cultivos } \\
\text { Tropicales (ICT), Instituto de Investigaciones de la Amazonía Peruana (IIAP), } \\
\text { Universidad Nacional de San Martín (UNSM) }\end{array}$ \\
\hline $\begin{array}{l}\text { Capacitación } \\
\text { y asistencia } \\
\text { técnica }\end{array}$ & $\begin{array}{l}\text { Goresam: Drasam, PEHCBM, PEAM, Dircetur, Citecacao } \\
\text { Cooperación internacional: TechnoServe, Devida, KfW, GIZ Alianza Perú Cacao } \\
\text { Gobierno central: Minagri, Senasa, Agrorural, Agoideas } \\
\text { Entes privados: cooperativas, asociaciones, Cámara de Comercio y Producción } \\
\text { de San Martín (CCPTSM) }\end{array}$ \\
\hline Certificadoras & $\begin{array}{l}\text { Biolatina, OCIA, Naturland, Fairtrade, Rainforest Alliance, Control Unión } \\
\text { Perú, UTZ, Imo Control }\end{array}$ \\
\hline Financieras & $\begin{array}{l}\text { IFIS nacionales: Agrobanco, BCP, BBWA, Caja Maynas, CSMP, Confianza } \\
\text { IFIS Internacionales: Rabobank, Alterfin, Root Capital }\end{array}$ \\
\hline $\begin{array}{l}\text { Servicios } \\
\text { directos a } \\
\text { nivel producto }\end{array}$ & $\begin{array}{l}\text { Maquila: Orquídea, Tesoro Amazónico } \\
\text { Poscosecha: Acopagro, Oro Verde, Allima Cacao, Makao, cooperativas pequeñas }\end{array}$ \\
\hline
\end{tabular}

Fuente: Drasam (2014), elaboración propia, actualizado 2016.

En la agenda del gobierno de Nueva Amazonía figura también la transformación de los productos agrícolas. Villanueva promueve personalmente la asociación de mujeres que producen chocolate en el distrito de Chazuta, al recomendarlas a ferias nacionales e internacionales y estableciendo contactos con posibles compradores de los chocolates promovidas por ellas, aprovechando de su rol de presidente regional y luego del presidente del Consejo de Ministros ${ }^{17}$. El valor agregado al café o cacao

17 Entrevista con César Villanueva, Lima, junio 2019. 
ha sido un tema importante en la agenda de promoción de desarrollo territorial en San Martín, con la idea de empoderar los pequeńos productores y transformadores. En San Martín, desde la década de 1980 el tema ambiental estuvo en la agenda política regional y social, impulsado por ONG como Cedisa y Apeco quienes en los tempranos 2000 ejecutaron un estudio justificatorio ${ }^{18}$ que resultó en la creación del primer área de conservación regional en Perú en 2005 (Paredes y Kaulard, 2019, en revisión). La política regional continúa con la visión de la conservación ambiental, a la cual integró un aprovechamiento «sustentable» de los recursos agrícolas, como el cacao, café, y últimamente, el aguaje ${ }^{19}$ y es apoyada por gran parte de la sociedad civil y las poderosas cooperativas agrarias. En otras regiones del Perú, en medio de una política de extracción de recursos mineros y sinergias entre el Estado y las empresas mineras, en esos tiempos, el discurso del gobierno fue diferente, y las ONG externas y ambientalistas ejercieron presión sobre la política gubernamental, lo cual resultó en conflictos ( $\mathrm{Li}, 2015)$. En cambio, en San Martín, partes influyentes de la sociedad y el gobierno regional están incrustados.

Asimismo, existe una demanda creciente de productos orgánicos y un consumidor sensibilizado en el mercado global, lo cual influencia el lado de la producción y transformación en los países exportadores de productos como el café y el cacao. La oferta de productos orgánicos y de comercio justo en San Martín que se ha desarrollado desde antes, se perfila aún más hacia estos mercados. Las dos grandes cooperativas de la región exportan casi exclusivamente a mercados orgánicos y fairtrade.

En la Tabla 2 se aprecia que la política de cadenas de valor continúa, mientras que hay diferencias en el tipo de producto que se fomenta.

Tabla 2. Cadenas de valor priorizadas

\begin{tabular}{|l|l|}
\hline Nueva Amazonía (2007-2014) & Fuerza Popular (2015-2018) \\
\hline Café & Cacao \\
Cacao & Café \\
Palma aceitera & Palma aceitera \\
Palmito & Plátano \\
Sacha inchi & Maíz amarillo duro \\
Pińón blanco para etanol (luego desapareció) & Arroz \\
(Ganadería) & Sacha inchi \\
(Turismo) & Limón \\
& Naranja \\
& Pijuayo para palmito \\
\hline
\end{tabular}

Fuente: Goresam, elaboración propia.

18 El estudio estimó que Cordillera Escalera contribuye más de 2 millones de dólares anuales con la generación de agua, con un potencial de hasta 14 millones de dólares.

19 Discurso de C. Villanueva en la PUCP, Perú, 2018 y entrevista con C. Villanueva, Lima, junio 2019. 
La política económica territorial, se llega a institucionalizar más en el gobierno regional del fujimorista Víctor Noriega (2014-2018) bajo el lema de "producción, protección e inclusión». En los dos gobiernos regionales analizados se observa que los productos priorizados por el Goresam de Villanueva tienen un mayor potencial de crecer en sistemas agroforestales menos nocivos que los productos adicionales incluidos por el gobierno de Víctor Noriega, si bien en el discurso de ambos se incorporan elementos de sostenibilidad ambiental e inclusión social con enfoque en la rentabilidad.

En las ponencias presentadas por los funcionarios de la Gerencia de Desarrollo Económico y la Drasam, se percibe la orientación hacia la "producción, protección e inclusión» y se lanza la «marca San Martín» que según un asesor del Gobierno regional promueve no solo la producción orgánica, sino también un no al trabajo infantil, la coca, la deforestación y el lavado de dinero ${ }^{20}$ (ver Figura 2). Esta línea es promovida por un gerente de desarrollo económico regional con años de experiencia en el PDA y diferentes organizaciones de la cooperación internacional.

Figura 2. Líneas de intervención estratégicas de producción, protección e inclusión

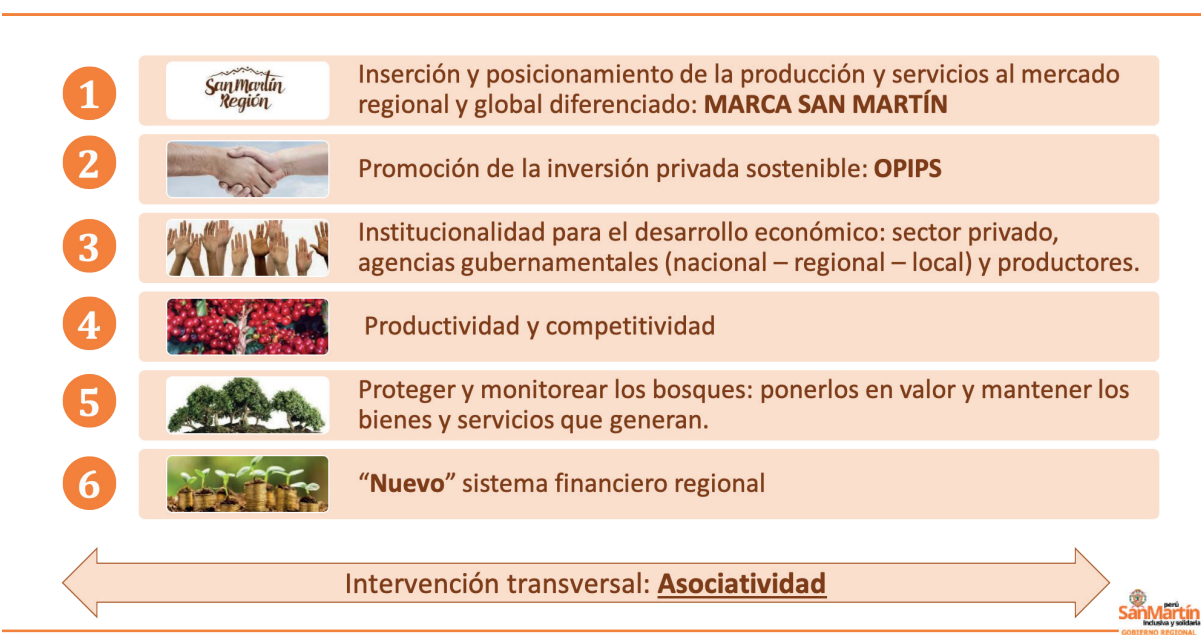

Fuente: Goresam, 2018.

La base institucional para la transición productiva fue construida en los dos períodos del gobierno de Nueva Amazonía y pudo ser continuada en la gestión de Fuerza Popular desde 2015. De tal manera, en el gobierno de Noriega se instalan las agencias de desarrollo económico local (ADEL) en las provincias de la región, impulsadas por el gerente de Desarrollo Económico Regional. Las ADEL

20 Entrevista con exasesor de César Villanueva, febrero 2018. 
están diseñadas para organizar la política regional a nivel provincial y buscar sinergias público-privadas para apoyar las cadenas de valor priorizadas, con un enfoque territorial. Este esfuerzo permite medir mejor el territorio y mejorar el sistema estadístico regional. Se ha desarrollado una planificación de acciones de las ADEL con sus gerentes que deben coordinar sus acciones con los gobiernos locales. Con las ADEL, el Goresam tendría un control más directo de las provincias. Los directores de las ADEL se orientan en la política económica definida por el Goresam, la cual implica el trabajo con las cadenas de valor priorizadas ${ }^{21}$.

En este acápite se evidenció que la política regional de los dos gobiernos de César Villanueva, es pionera en varios aspectos del desarrollo económico con enfoque agrícola. Villanueva tempranamente en su gobierno se opone a la visión de USAID y la Oficina de Naciones Unidas contra la Droga y el Delito (UNDOC, por sus siglas en inglés) que promueven enfocarse solo en zonas cocaleras con los programas de desarrollo alternativo. Enfatiza que se necesita un desarrollo integral para la región. Por otra parte, la incorporación de productos orgánicos en la política regional en un momento, cuando no estaba aún «en vogue» en otros países latinoamericanos u otras partes del Perú, se debe probablemente a su formación y activismo ambientalista, pero también a influencias de redes de la cooperación internacional, a la cual su ONG Cedisa estuvo vinculada. Con la gestión de Noriega se ve la continuidad de la política de las cadenas de valor «alternativas», pero se da un matiz de «inclusión social» o justicia a la política, la cual no es tan visible en la gestión de Villanueva en la cual domina la visión ambientalista, como se demuestra por ejemplo en el caso de la primera área regional protegido (Paredes y Kaulard, 2019, en revisión).

\section{CONTINUIDAD Y PROFESIONALIZACIÓN POR SINERGIAS ESTADO-SOCIEDAD}

\subsection{Think and action tank}

La incrustación, como aspecto importante de las sinergias en San Martín se expresa en la política de recursos humanos del gobierno regional. Varios funcionarios y funcionarias del gobierno regional trabajaron antes en la cooperación internacional u ocuparon puestos en instituciones cercanas al apoyo a la producción local, formando parte de la red DER en San Martín. Este tipo de sinergias a nivel local ofrece oportunidades para dar continuidad y difundir un mensaje de producción sustentable a la sociedad.

En el período de 2006 a 2016, los gobiernos regionales muestran relativa continuidad de personal en posiciones clave de la institución, como por ejemplo en

\footnotetext{
${ }^{21}$ Observaciones en taller con directores de las ADR en Moyobamba, febrero 2017.
} 
la gerencia general. Con el apoyo de la cooperación internacional, se había preparado la transición de la gestión de Nueva Amazonía a la de Fuerza Popular en 2015, que aportó a la permanencia de personal o la contratación de asesores/as del think and action tank constituido por César Villanueva. Aunque la sostenibilidad de la política y gestión regional de Nueva Amazonía no se manifestó en un triunfo de su partido en las elecciones de 2018, Villanueva dejó implementado este stock de funcionarios con experiencia en la gestión pública y el desarrollo de estrategias. Posiblemente, si Villanueva no hubiera respondido a la llamada del presidente Humala en 2013 para asumir la Presidencia del Consejo de Ministros, lo cual requirió que el vicepresidente Javier Ocampo lo reemplace en el puesto de gobernador regional, los resultados de las elecciones de 2018 hubieran sido otros. Un análisis de trece personas vinculadas al think and action tank de San Martín demuestra resultados sorprendentes (ver Anexo 1). Las personas clave en la reforma institucional y transición productiva, pasan de un gobierno regional, ascienden a instituciones y posiciones clave en el Estado nacional o rotan entre organizaciones de la cooperación internacional u ONG y el gobierno regional. Como se nota en el siguiente gráfico de resumen, nueve de las trece personas a las que se hizo un seguimiento, han trabajado mínimamente en dos tipos de instituciones; sea a nivel del Estado nacional, en el gobierno regional y/o en organizaciones de la cooperación internacional y la sociedad civil. Tres personas trabajaron incluso en los tres tipos de instituciones en diferentes momentos de su carrera (ver Figura 3).

Figura 3. Rotación de personal entre Estado nacional, subnacional, cooperación internacional y sociedad civil

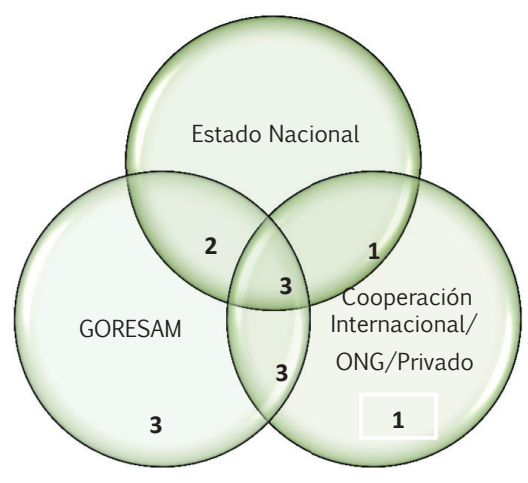

Según Villarán y Hurtado (2012), quienes elaboraron una propuesta de factores de éxito del Modelo San Martín, una de las primeras variables es la estrategia y las acciones de desarrollo productivo-económico. Esta variable está basada, por un lado, 
en la continuidad de las políticas, programas y actividades del desarrollo alternativo. Por otro lado, requirió de la continuidad de muchos funcionarios de alto nivel, con conocimiento y experiencia en los diversos temas involucrados, que permitieron plasmar estas políticas en la región. La continuidad del personal ha contribuido a que exista una narrativa homogénea en la región, en cuanto al desarrollo territorial y las cadenas de valor orgánicas y/o de comercio justo.

El Goresam logra instalar un equipo profesional institucional que principalmente proviene de la región San Martín y que está comprometido con el desarrollo territorial y la gestión del gobierno regional, tanto a nivel de gerentes, destacando la gerencia general, gerencias regionales y proyectos especiales, como de un grupo de profesionales jóvenes en unidades clave, como la Subgerencia de Planeamiento Estratégico y Estadística Regional y la Oficina de Diálogo y Sostenibilidad (Molina y Arguedas, 2015).

Asimismo, para la reforma y modernización del Goresam, Villanueva conforma un equipo técnico regional de reingenería organizacional, que recibe asesoría técnica externa, y el cual puede mantenerse de manera sostenida por cinco años de gestión (Molina y Arguedas, 2015). Con este think and action tank, se ha construido un núcleo directivo y profesional sólido que tiene clara la dirección estratégica y las necesidades de acción. El factor tiempo y la continuidad de dos gobiernos de la gestión de Villanueva aportan también a la institucionalización del enfoque de modernización y formalización institucional. Un tema de vanguardia promovido por Villanueva es la distinción de funciones de gobierno y administración. $\mathrm{Su}$ equipo de confianza es integrado por el gerente general regional quién toma el liderazgo en funciones administrativas para que los funcionarios a cargo asuman la toma de decisiones de carácter más operativo y la alta dirección se concentre en los aspectos estratégicos, de liderazgo institucional y seguimiento a resultados de planes y políticas regionales (Molina y Arguedas, 2015). En una entrevista, César Villanueva expresa que «tanto una Presidencia Regional sin un equipo de soporte, como un equipo de lujo sin un liderazgo que lo conduzca, no sirven. Sin liderazgo, ni el mejor diseño organizacional sirve» (César Villanueva, citado en Molina y Arguedas, 2015, p. 43).

La red del «think and action tank $D E R$ » de la región San Martín, principalmente alrededor de Villanueva y sus gerentes de desarrollo económico y gerencia general, se extiende también a instituciones y empresas privadas y de la cooperación internacional que además fueron capacitados en los mismos talleres y eventos sobre el tema del desarrollo económico territorial, organizados por una serie de cooperantes y ONG, como GIZ (antes InWEnt), ITDG, Swisscontact y el servicio holandés SNV. Esta construcción de capital social que se refleja en acciones conjuntas traspasó la 
frontera entre Estado y sociedad. Es notorio que los miembros de este grupo tienen un lenguaje común y un mensaje uniformizado hacia afuera ${ }^{22}$.

No obstante, el desarrollo de capacidades no solo es impulsado por la cooperación internacional, sino aquí también el Goresam puso su propio sello. La gestión de Villanueva enfatiza la frase: «El mejor canon que tenemos es nuestra gente», aludiendo a los pocos recursos que la región San Martín obtiene del canon minero. Esta frase también es retomada por la gestión posterior de Fuerza Popular y afirma que por tener poco canon minero, la región no estaría afectada por la «maldición de los recursos» ${ }^{23}$. La gestión de Nueva Amazonía pone énfasis en el fortalecimiento de capacidades de personas a nivel regional, para mejorar la productividad, hacer innovaciones y profesionalizarlas como asesores, funcionarios directivos o administrativos. La política de la Autoridad Nacional del Servicio Civil (Servir) es integrada en la gestión del Goresam.

Esta estrategia requirió inversión en capacidades, desde la educación primaria. Por ello, luego de haberse convencido de la propuesta de USAID en alianza con el Ministerio de Educación para implementar una Propuesta Pedagógica Integral y Apoyo a la Descentralización Educativa (AprenDes) en San Martín comozona piloto, Villanueva está motivado para invertir tiempo y recursos en esta estrategia para mejorar la calidad de la educación primaria rural. El programa hace un análisis positivo después de sus cuatro años de funcionamiento, en cuanto al fortalecimiento delaautonomía escolary la mejora dela calidad del aprendizaje (López, s/f).

Los estrategas de Villanueva son clave para seguir adelante con la política regional «sustentable». Sin embargo, se requirió también de ejecutores agrotécnicos de esta política. Este stock de recursos humanos se logró también a través de la incrustación público-privada en San Martín.

\subsection{Tigres y tigresas}

A través de la profesionalización y permanente capacitación recibida por el Goresam y las organizaciones de la sociedad civil o cooperación internacional en el tiempo, una nueva figura importante en el imaginario colectivo se ha cristalizado en las zonas productivas. Son los llamados «tigres«, los técnicos o extensionistas del campo, y «tigresas«, aunque está última expresión es utilizada solo por este estudio

22 Se pudo observar en las entrevistas con los funcionarios y funcionarias del Goresam $(2017,2018$, 2019), así como en las presentaciones Powerpoint y los debates políticos de los candidatos al gobierno regional, 2018.

23 Este término se refiere a los modelos de extracción minera y economías basadas principalmente en los hidrocarburos, cuya maldición es que, aunque reciben grandes cantidades de fondos por el canon, no han tenido impactos positivos en la mejora de los niveles de pobreza y el IDH. 
y no en el lenguaje coloquial, para incluir en el análisis a las expertas en la producción de chocolate fino y la catación del cacao, que tienen un rol clave en las zonas cacaoteras. Estos expertos y expertas técnicos están tanto en el sector público, como en el sector privado-empresarial y de la sociedad civil, por lo tanto son expresión de la incrustación y facilitan las sinergias público-privadas.

Cuando se viaja a las zonas cacaoteras de San Martín, como por ejemplo Chazuta, Juanjui o Tocache, uno se encuentra con los «tigres». Mayormente, son sanmartinenses y pertenecen a redes formales e informales de la región, unidos por su casa de estudios, trabajo anterior, religión, familia o amigos. Son personas que son reconocidas por sus chalecos con el logo de su institución, por ejemplo, la dirección agraria regional (Drasam). Otros técnicos pertenecen a uno de los proyectos especiales desconcentrados del Goresam. Últimamente, también se encuentran «tigres» de las cooperativas cacaoteras o de la empresa privada Machu Picchu. Muchos de ellos han sido formados y luego contratados por el PDA, para «romper los montes», es decir acercarse a las zonas alejadas donde viven pocas personas que sembraban coca. Los «tigres» son reconocidos por la mayoría de los agricultores como expertos en temas técnicos del cacao, como extensionistas de las buenas prácticas de cultivo, poda, cosecha y poscosecha. Sin embargo, no pueden abastecer a todas las zonas donde se necesita su ayuda, y dependiendo de la coyuntura financiera de los que los pagan, desaparecen o reaparecen. La figura de los «tigres» se parece a los técnicos del desarrollo rural descritos por Asensio en las zonas altoandinas, que también son reconocidos por los chalecos, su fuerte símbolo de identificación institucional y que trabajan en temas de desarrollo productivo, pero también en el fortalecimiento de la asociatividad (Asensio, 2016).

En mi trabajo conjunto con expertos técnico-productivos del Goresam, los "tigres públicos», observé su alto grado de compromiso para apoyar a una mejor tecnificación y productividad, pero también su desempeño en registrar información cuantitativa sobre la producción, rendimiento y rentabilidad del cacao, así como una tendencia de quitar «todo lo social» de sus observaciones e interpretaciones de la realidad. La noción de un cacaotero productivo, anónimo quien toma decisiones económicas racionales (rational choice) parece ser un supuesto no cuestionable entre los técnicos regionales. Esto se manifiesta también en que los conflictos por posesión y titulación de tierras entre comunidades indígenas, colonos y mestizos no suelen ser abarcados.

Las «tigresas" son menos visibles y no son nombradas como tales, sino como «técnico»o «ingeniero». Son mujeres capacitadas en la producción de chocolates, en su mayoría con estudios universitarios, que han recibido además un perfeccionamiento profesional por programas como el PDA. Mientras sus colegas hombres son mayormente agrónomos y asesoran en la parte del cultivo y la poscosecha, ellas son 
ingenieras o técnicas industriales o alimentarias y se han especializado en la transformación del cacao en chocolates y bombones finos, así como en sus empaques y marketing de estos productos. Ellas trabajan en los programas especiales del gobierno regional, en su propia empresa de chocolates y/o como asesoras contratadas por una ONG o la cooperación internacional. Algunas de ellas son también productoras de cacao o esposas de cacaoteros que han sido incentivadas por el PDA para producir chocolates a pequeña escala y ahora se dedican a enseñar estas habilidades a otras personas. Tradicionalmente, el procesamiento del cacao en chocolates, bombones, o la cocción del tradicional «upe», una mezcla de maíz con cacao, ha sido el rol de las mujeres, aunque últimamente se observan cambios en algunas familias de las zonas cacaoteras.

En resumen, los «tigres», así como las «tigresas» suelen tener una buena formación técnica con una sensibilidad ambiental marcada, y trabajan para el gobierno regional y organizaciones privadas. Sin embargo, especialmente los expertos hombres no han tenido una formación en ciencias sociales que permitiría ampliar su comprensión de las instituciones, actores y los sistemas complejos de relaciones en sus territorios. Las universidades de San Martín no ofrecen carreras como sociología o antropología, por lo cual la enseñanza en ciencias sociales se reduce a la economía y existe una prevalencia de carreras de las ciencias «duras» como agronomía, agroforestería e ingeniería ambiental. No obstante, estas personas son un pilar importante en la continuidad de la política de cadenas de valor sustentables, así como en la difusión de un conocimiento de expertos altamente especializado y necesario para la inserción de los productos locales en los mercados globales de nichos de comercio orgánico y fairtrade.

\section{Conclusiones}

En este estudio se ha demostrado que, en un contexto nacional de rechazo a la intervención del Estado en la economía, San Martín constituye una excepción. El Estado nacional permitió esta intervención por la lucha contra el narcotráfico y la presión de los Estados Unidos para alcanzar éxitos visibles.

El liderazgo del gobierno regional en la política alternativa fue desarrollado por el carismático C. Villanueva quien tuvo el poder de convocatoria para crear sinergias entre el Estado regional, los gobiernos locales, el sector privado y la sociedad civil, lo cual aportó sustancialmente al «Milagro de San Martín», en la sustitución de la coca por cultivos alternativos. No obstante, el gobierno regional aspiró a una transformación productiva más: la sustitución de la coca por productos relativamente «sustentables» y la creación de un valor agregado a los productos. En esta línea, la política económica regional iniciada por el movimiento regional Nueva Ama- 
zonía se perfiló a través del tiempo como una política económica regional con sello propio, basada también en una reforma de modernización del gobierno regional. El enfoque del «más allá de la competitividad», especialmente en la producción y el procesamiento de los productos "alternativos» y sustentables, como el café y el cacao orgánico, se ha discutido y manifestado en los proyectos implementados en San Martín antes de que se haya introducido en otras zonas del país. El punto de inflexión en la historia de la política económica se dio con el ingreso de Villanueva, mientras que el gobierno anterior aprista del presidente regional Ramirez tuvo un enfoque de grandes proyectos de infraestructura y agricultura extensiva, basada en alianzas con los arroceros y maiceros de la región. La política de las cadenas de valor continúa desde el gobierno de Nueva Amazonía al gobierno de Fuerza Popular, aunque con matices diferentes en la priorización de los productos.

La política regional está basada en una reforma del Estado, que no solo se concentró en lo técnico, sino también en lo político (Molina y Arguedas, 2015). Sus elementos clave son, por un lado, una visión de desarrollo regional más allá de los límites del departamento y liderazgo para expresarla; junto con una visión concretada en políticas públicas regionales y un equipo cohesionado en la dirección institucional, así como una política innovadora y eficaz de gestión de la inversión pública con instrumentos de gestión unificados para todo el pliego (Molina y Arguedas, 2015).

Se demostró que una red de profesionales políticos y administrativos, el think and action tank, formados a través de una incrustación del Estado con la sociedad en temas del agro y la agroindustria, son esenciales para la continuidad de la estrategia y política económica regional. Los actores cambian su función y la organización donde trabajan, así que por tiempos pertenecen al gobierno regional, y luego se encuentran en el Estado nacional, en agencias de desarrollo, en ONG o viceversa. A través de este pool de funcionarios y asesores, así como los técnicos «tigres» $\mathrm{y}$ «tigresas» se ha difundido el mensaje de la «economía verde» con valor agregado por la transformación de los productos en la región. En campo se observa una nueva sensibilidad ambiental entre los productores agrícolas quienes conocen la importancia de utilizar fertilizantes y plaguicidas orgánicos. La incrustación de autoridades y personal del gobierno regional con la sociedad civil y el sector privado ha llevado a sinergias relativamente positivas en cuanto a la promoción de cadenas de valor «alternativas", posibilitando que la cooperativa Acopagro del sur de la región llegue a ser el primer exportador de cacao orgánico del país.

Varias conclusiones emergen de este análisis. Por un lado, la evidencia presentada mostró que la comunidad epistémica del «think and action tank» de San Martín fue clave para el establecimiento del modelo y la difusión de los mensajes clave en la región. Las raíces regionales y la incrustación de este equipo en la sociedad de San 
Martín, permitió la generación de una identidad de región «verde» con cadenas de valor orgánicas y «justas» del cacao. Con esta actitud y la confluencia de «critical junctures» — como por ejemplo, cambios en la actitud del consumidor global o la participación de las autoridades regionales en intercambios clave con sus pares en Colombia y Costa Rica- César Villanueva y su equipo lograron romper, en parte, la historia productiva previa de la región, que estuvo basada en la venta a acopiadores «de paso» de productos primarios. Las sinergias creadas por los gobiernos regionales a partir de Villanueva no se desarrollaron solo con los actores económicos más privilegiados de la región, sino principalmente con los pequeños productores y productoras, con los cuales se estableció una relación cordial y personalizada y de confianza $^{24}$.

Sobre la pregunta de la prevalencia de la estructura o la agencia en este caso, se puede concluir que, por un lado, la estructura para el desarrollo productivo, p.ej. la infraestructura vial, es un factor importante, pero no suficiente para explicar el «éxito» del desarrollo regional en San Martín. La incrustación ha sido, más bien, el factor clave que permitió construir ganancias de desarrollo en redes relativamente resilientes de desarrollo económico territorial. Estas redes de confianza entre personas de la región, se han podido escalar más allá de lo local, a través de los contactos y amistades internacionales de César Villanueva, y el apoyo de la cooperación internacional. La política internacional que promueve el desarrollo alternativo sustentable encontró pocas fricciones con el «sustrato regional» de una sociedad civil organizada y sensible a temas ambientales. Definitivamente, las sinergias han sido facilitadas por una burocracia relativamente robusta y la competencia política de Villanueva, lo cual aportó a que San Martín se perfile como la «niña engreída» de la cooperación internacional.

En un engranaje complejo de gerencias, direcciones sectoriales regionales, proyectos especiales y agencias de desarrollo económico local (ADEL), así como las redes de profesionales que dan vida a la estructura institucional, se encuentran los resultados de esta política sui generis que, no obstante, no queda sin contradicciones y desafíos. A pesar de la política económica y las múltiples iniciativas de los gobiernos regionales de 2006-2016 en productos «sustentables» de la selva, se observa la extensión de la frontera agrícola que presiona sobre el bosque. Las iniciativas de cacao en sistemas agroforestales quedan amenazadas por la ampliación de sistemas productivos extensivos como el maíz y el arroz que cuentan con una larga historia en la región San Martín. Si bien el enfoque de producción susten-

\footnotetext{
24 Tras los últimos sucesos a nivel político con la sospecha de corrupción y tráfico de influencias, la imagen de Villanueva como generador del «milagro» has sido fuertemente afectada y queda por observar si en su región es capaz de recuperar la confianza de la sociedad civil.
} 
table se discutió en San Martín antes de que se debata en otras zonas del país, algunos autores afirman que - a pesar de ello - no se han cuestionado las bases más profundas de un modelo neoextractivista, como se demostró en el caso de bio-trade del sacha inchi en San Martín (Köppel, 2017). Así que, en un debate de los candidatos a la gobernación regional, César Rengifo, quien es muy cercano a Villanueva y representa la política actual de Nueva Amazonía, manifiesta sus planes de política agrícola, lo que nos deja algunas interrogantes sobre la factibilidad de la combinación de desarrollo económico y ambiental en el contexto de la región. «En el tema de la competitividad, debemos mantener el aporte del 6,2\% al PBI. La competitividad en las principales cadenas de valor [es importante]; si no tenemos productividad, asistencia técnica, innovación tecnológica, estas cadenas seguirán presionando sobre el bosque. Y para que no presionen sobre el bosque y evitemos la deforestación, tienen que ser rentables. En los próximos diez años podemos llegar a cero deforestación $»^{25}$.

Los commodities «alternativos» como el cacao y café se prestan para la promoción de la justicia social y el cuidado medioambiental, ya que son pequeños productores quienes suelen tomar un rol protagónico en su producción. En esta línea, los gobiernos regionales de San Martín han hecho un esfuerzo y lograron sensibilizar a un gran número de productores y productoras para la producción orgánica, y en menor grado, para el comercio justo. Queda por ver si las bases de la transformación productiva sanmartinense son suficientemente firmes para ser sostenibles en el tiempo y generalizar un enfoque de "ecología productiva sustentable» en la región, lo cual significaría un cambio sustancial de los sistemas productivos hacia la pequeña producción orgánica para mercados nicho.

25 Transcripción de debates políticos de candidatos a gobernador regional, Tarapoto, campaña electoral 2018. 
Anexo 1. Sinergias Estado - Sociedad

\begin{tabular}{|c|c|c|c|c|c|c|}
\hline & & $\begin{array}{l}\text { Gobierno } \\
\text { Ramírez }\end{array}$ & $\begin{array}{c}\text { Gobierno } \\
\text { Villanueva }\end{array}$ & $\begin{array}{l}\text { Gobierno } \\
\text { Noriega }\end{array}$ & $\begin{array}{c}\text { Estado } \\
\text { nacional }\end{array}$ & $\begin{array}{c}\text { Cooperación } \\
\text { Internacional/ } \\
\text { ONG }\end{array}$ \\
\hline 1 & C. Villanueva & & $\begin{array}{l}\text { Presidente } \\
\text { Gobernador } \\
\text { regional }\end{array}$ & & $\begin{array}{l}\text { Presidente } \\
\text { del Consejo } \\
\text { de Ministros } \\
\text { (2014 y a partir } \\
\text { de 2018) }\end{array}$ & $\begin{array}{l}\text { Gerente ONG } \\
\text { Cedisa }\end{array}$ \\
\hline 2 & J. L. Vela & & $\begin{array}{l}\text { Gerente } \\
\text { general }\end{array}$ & $\begin{array}{l}\text { Gerente de } \\
\text { Planeamiento } \\
\text { y Presupuesto } \\
(2017) \\
\end{array}$ & & \\
\hline 3 & C. Rengifo & & Asesor & & PCM & ONG Cedisa \\
\hline 4 & I. Encomenderos & & $\begin{array}{l}\text { Gerente de } \\
\text { Desarrollo } \\
\text { Económico } \\
\text { (2012-2014) }\end{array}$ & & PCM & \\
\hline 5 & I. Encomenderos & & & & & $\begin{array}{l}\text { Coordinador } \\
\text { socioeconómico } \\
\text { de Conservación } \\
\text { Internacional, Perú } \\
\text { Gerente de Cámara } \\
\text { de Comercio TPP }\end{array}$ \\
\hline 6 & E. Delgado & & & $\begin{array}{l}\text { Gerente de } \\
\text { Desarrollo } \\
\text { Económico } \\
(2016-2018)\end{array}$ & & $\begin{array}{l}\text { Asesor técnico } \\
\text { en ITDG, PDA, } \\
\text { TechnoServe, } \\
\text { Chemonics } \\
\text { (USAID) }\end{array}$ \\
\hline 7 & N. Bartra & & & Gerente ARA & & $\begin{array}{l}\text { Jefe de ONG } \\
\text { Fundavi }\end{array}$ \\
\hline 8 & W. Gallegos & $\begin{array}{l}\text { Gerente } \\
\text { regional de } \\
\text { Desarrollo } \\
\text { Económico }\end{array}$ & & $\begin{array}{l}\text { Gerente } \\
\text { Drasam }\end{array}$ & & \\
\hline 9 & C. Torre & & $\begin{array}{l}\text { Asesor planes } \\
\text { de gobierno y } \\
\text { reorganización } \\
\text { Asesor del } \\
\text { PEHCBM }\end{array}$ & $\begin{array}{l}\text { Asesor planes } \\
\text { degobiernoy } \\
\text { reorganización }\end{array}$ & & \\
\hline 10 & D.delAguilar & & $\begin{array}{l}\text { Asesor Gerencia } \\
\text { Regional de } \\
\text { Desarrollo } \\
\text { Económico }\end{array}$ & & $\begin{array}{l}\text { Asesor del } \\
\text { Ministerio de } \\
\text { Agricultura y } \\
\text { Riego }\end{array}$ & $\begin{array}{l}\text { Director } \\
\text { proyecto PRA } \\
\text { (2002-2004) } \\
\text { Director regional } \\
\text { PDA San Martín } \\
\text { (Chemonics } \\
\text { 2004-2012) }\end{array}$ \\
\hline
\end{tabular}




\begin{tabular}{|l|l|l|l|l|l|l|}
\hline 11 & D. Vásquez & $\begin{array}{c}\text { Gobierno } \\
\text { Ramírez }\end{array}$ & $\begin{array}{c}\text { Gobierno } \\
\text { Villanueva }\end{array}$ & $\begin{array}{c}\text { Gobierno } \\
\text { Noriega }\end{array}$ & \multicolumn{1}{|c|}{$\begin{array}{c}\text { Estado } \\
\text { nacional }\end{array}$} & $\begin{array}{c}\text { Cooperación } \\
\text { Internacional/ } \\
\text { ONG }\end{array}$ \\
\hline 12 & E. Agreda & & $\begin{array}{l}\text { Gobierno } \\
\text { Regional 2019 } \\
\text { (Bogarín): } \\
\text { Gerente de } \\
\text { Desarrollo } \\
\text { Económico }\end{array}$ & $\begin{array}{l}\text { Responsable de } \\
\text { Asistencia Técnica } \\
\text { Prodatu (KfW), } \\
2007\end{array}$ \\
\hline 13 & S. Reátegui & & Gerente ARA & & $\begin{array}{l}\text { Foncodes } \\
\text { (responsable } \\
\text { de núcleos } \\
\text { ejecutores) }\end{array}$ & $\begin{array}{l}\text { Asesor técnico } \\
\text { en ITDG, PDA, } \\
\text { TechnoServe, } \\
\text { Chemonics } \\
\text { (USAID) }\end{array}$ \\
\hline
\end{tabular}

\section{REFERENCIAS BIBLIOGRÁFICAS}

Agencia Andina (2011). USAID/Perú y región San Martín renuevan acuerdo para impulsar el desarrollo. Recuperado de http://www.andina.com.pe/agencia/noticia-usaidperu-yregion-san-martin-renuevan-acuerdo-para-impulsar-desarrollo-358115.aspx

Alburquerque, F. y Dini, M. (2008). Guia de Aprendizaje sobre integración productiva y desarrollo económico territorial. Washington DC: BID, Fondo Multilateral de Inversiones.

Alburquerque F. y Pérez Rozzi, S. (2013). El desarrollo territorial: enfoque, contenido y politicas. Mesa de programas. Recuperado de http://www.conectadel.org/wpcontent/ uploads/downloads/2013/09/EL-ENFOQUE-SOBRE-EL-DESARROLLOTERRITORIAL-doc-Mesa-de-Programas.pdf

Asensio, R. H. (2016). Los nuevos incas: la economía politica del desarrollo rural andino en Quispicanchi (2000-2010). Lima: IEP.

Burnyeat, G. (2018). Chocolate, Politics and Peace-Building. An Ethnography of the Peace Community of San José de Apartadó, Colombia. Cham: Palgrave Macmillan, Springer Nature.https://doi.org/10.1007/978-3-319-51478-9

Cepal (2019). Website. Recuperado dehttps://www.cepal.org/es/temas/desarrollo-territorial. Congreso de la República del Perú (2003). Ley Orgánica de Municipalidades (No 27972), artículos VI y 86.

Espinosa, O. (2009). ¿Salvajes opuestos al progreso?: aproximaciones históricas y antropológicas a las movilizaciones indígenas en la Amazonía peruana. Anthropologica, 27(27), 123-168. Recuperado de http://revistas.pucp.edu.pe/index.php/anthropologica/ article/ view/1602

Esser, K., Hillebrand, W., Messner, D. y Meyer-Stamer, J. (1994). Competitividad sistémica: competitividad internacional de las empresas y politicas requeridas. Berlín: Instituto Alemán de Desarrollo.

Evans, P. (1995). Embedded autonomy: States and industrial transformation. Princeton, NJ: Princeton University Press. https://doi.org/10.1515/9781400821723 
Evans, P. (1996). Government action, social capital and development: Reviewing the evidence on synergy. World Development. Elsevier https://doi. org/10.1016/0305-750X(96)00021-6

Gallegos Arévalo, W. (2015). Diario Voces. https://www.diariovoces.com.pe/46769/ max-henry-ramirez-garcia-presidente-regional

García, A. (2007, 28 de octubre). El sindrome del Perro del Hortelano. Lima: El Comercio.

Gereffi, G., Humphrey, J. y Sturgeon, T. (2005). The governance of global value chains. Review of International Political Economy, 12(1)78-104. https://doi. org/10.1080/09692290500049805

Greif, A. (2006). Institutions and the path to the modern economy: Lessons from medieval trade. Cambridge: Cambridge University Press. https://doi.org/10.1017/ CBO9780511791307

Haas, P. (1989). Do regimes matter? Epistemic communities and Mediterranean pollution control. International Organization, 43, 377-403 https://doi.org/10.1017/ S0020818300032975

Köppel, J. (2017). The imperial rationality within BioTrade: A contribution to the neoextractivist debate. Alternautas, 4(2), 76-92.

Lakhani, T., Kuruvilla, S. y Avgar, A. (2013). From the firm to the network: Global value chains and employment relations theory. British Journal of Industrial Relations, 51(3), 440472. https://doi.org/10.1111/bjir.12015

Lane, C. y Probert, J. (2009). National Capitalisms, Global Production Networks. Fashioning the Value Chain in the UK, USA, and Germany. Oxford: Oxford University Press.https:// doi.org/10.1093/acprof:oso/9780199214815.001.0001

Li, F.(2015), Unearthing Conflict: Corporate Mining, Activism, and Expertise in Peru. Durham, NC: Duke University Press. https://doi.org/10.1215/9780822375869

Linton, A. (2012). Fair trade from the ground up: new markets for social justice. Seattle, WA: University of Washington Press.

López, I. (s/f). Propuesta pedagógica integraly apoyo a la descentralización educativa. La evaluación de impacto y sus resultados. S/l.: s/e.

Mesopartner/SISTME (2014). Thematic Study of Regional Economic Development in Latin America and the Caribbean. Buenos Aires, Washington: Fomin.

Molina, R. y Arguedas, C. (2015). Sistematización de la experiencia de modernización y reforma institucional del Gobierno Regional de San Martin. Lima: GIZ.

March, J. G. (1997), Understanding how decisions happen in institutions. Organizational Decision Making. Cambridge: Cambridge University Press. https://doi.org/10.1017/ CBO9780511584169.004

North, D. C. (1990). Institutions, institutional change and economic performance. Cambridge: Cambridge University Press. https://doi.org/10.1017/CBO9780511808678

North, D. C. (2005). Unterstanding the process of institutional change. Princeton, NJ: Princeton University Press. 
Orihuela, J. C. (2017). Assembling participatory Tambopata: Environmentality entrepreneurs and the political economy of nature. Forest Policy andEconomics, 80(July), 52-62. https://doi. org/10.1016/j.forpol.2017.03.010

Orihuela, J. C. (2019 a). Embedded Countermovements: The Forging of Protected Areas and Native Communities in the Peruvian Amazon. New PoliticalEconomy, 25(1), 140155. https:// doi.org/10.1080/13563467.2019.1570101

Orihuela, J. C. (2019 b). The Political Economy of the Developmental State in Latin America. Nueva York, NY: Oxford University Press. https://doi.org/10.1093/ acrefore/9780190228637.013.1660

Orr, A., Donovan, J. y Stoian, D. (2015). Smallholder Value Chains as Complex Adaptive Systems. A Conceptual Framework. Socioeconomic Discussion Paper Series ICRISAT, Series Paper $\mathrm{N}^{\circ} 36$.

Ostrom, E. (2008). Institutions and the environment. Economic Affairs, 28(3), 24-31. https://doi. org/10.1111/j.1468-0270.2008.00840.x

Paredes, M. y Kaulard, A. (2019). Fighting the Climate Crisis in Persistently Unequal Land Regimes: Natural Protected Areas in the Peruvian Amazon (bajo revisión).

Pierson, P. (2004). Politics in time: history, institutions and social analysis. Princeton, NJ: Princeton University Press. https://doi.org/10.1515/9781400841080

Polanyi, K. (2001[1944]). The great transformation. Nueva York, NY: Rinehart \& Co., Inc.

Roseberry, W.(1996). The Rise ofYuppie Coffees and the Reimagination ofClass in the United States.AmericanAnthropologist, NewSeries, 98(4), 762-775. https://doi.org/10.1525/ a.1996.98.4.02a00070

Scott, R., 2008. Approaching adulthood: the maturing of institutional theory. Theory and Society, 37, 427-442. https://doi.org/10.1007/s11186-008-9067-z

Skocpol, T. (1985). Bringing The State Back In Strategies of Analysis in Current Research. En P. Evans, D. Rueschemeyer y T. Skocpol (eds.), Bringing The State Back In (pp. 3-37). Cambridge: Cambridge University Press. https://doi.org/10.1017/ CBO9780511628283.002

Springer-Heinze, A. (2017). ValueLinks 2.0. Manual on Sustainable Value Chain Development. Eschborn: GIZ.

Villarán, F. y Hurtado, F.T. (2012). El modelo de desarrollo alternativo de la región San Martín: unestudio de caso de desarrollo económico local. Lima: UNODC. 